\title{
HEART INJURY- A GENERAL SURGICAL EMERGENCY An Account of 2 Cases of Penetrating Chest Injury Involving the Heart
}

\author{
By Miles Fox, M.B., F.R.C.S. \\ Resident Surgical Officer, Ancoats Hospital, Manchester
}

Ability to carry out prompt exploratory thoracotomy in injuries of the heart should be within the capability of every general surgeon, who is the person usually confronted first with such an emergency.

Every penetrating injury of the thorax should be suspected of involving important cardiovascular structures, even though indicative signs and symptoms are absent. The mechanism of injury, position, extent of the wound and the general condition of the patient may be quite misleading. Two cases are described.

\section{Case I}

Mr. T. W., aged 39 years. Admitted on August 4 , 1957.

History.-One hour prior to admission, while standing on household steps cutting a hedge, he fell on to the pointed end of a metal railing in the hedge. The spike entered the left side of the chest. He managed to lift himself off the spike and crawl into the house.

Examination.-He was pale and sweating and complaining of pain in the left side of the chest. His respirations were shallow, $P .=84 /$ minute, regular, B.P. $=130 / 65$. An irregular deep laceration, I $\mathrm{cm}$. long, was present over the 6 th intercostal space in the nipple line. A smaller superficial puncture wound was present just posterior to the anterior axillary line higher up. Surgical emphysema surrounded both the wounds. There were no signs of lung collapse or effusion. Heart sounds were normal. Slight tenderness, but no guarding was present in the left hypochondrium.

Treatment.-Under general anaesthesia and with blood transfusion in progress the wounds were probed. The upper and lateral wound was superficial. It was cleaned and sutured. The anterior wound admitted a probe upwards into the chest cavity towards the heart. Excision of the wound edges revealed the track to extend through the $5^{\text {th }}$ intercostal space. The $5^{\text {th }}$ rib was incompletely fractured and dislocated at the sterno-chondral junction. On extending the wound it could be seen that both the pleural and pericardial cavities had been opened, there being a $\mathbf{I}-\mathrm{cm}$. laceration in the pericardium, through which a small amount of blood escaped with each heart beat. The pericardium was opened and a laceration of the left ventricle was seen. This was about 2 to $3 \mathrm{~cm}$. long and I cm. wide, just to the left of the anterior descending branch of the left coronary artery. A branch of the same artery was running down the other margin of the wound and was steadily oozing. It was found impossible to insert sutures satisfactorily to close the wound because of the proximity of the vessels to the wound edges. A piece of muscle from the chest wall was then fitted into the gap and sutured in place without tension. The pericardium was loosely sutured. No other injury was found. The chest was closed, leaving an intercostal drain.

Progress.-This was satisfactory except for a small left pleural effusion which resolved quickly, and multiple extrasystoles which subsided after administration of procaine amide. He was discharged from hospital after four weeks. When seen again one month later he was symptomfree and was about to resume his work as a chemist. E.C.G. records showed changes similar to infarction in the antero-lateral wall of the left ventricle. He has remained symptom-free.

\section{Case 2}

Master K. B., aged 12 years. Admitted on March 4, 1958.

History.-While climbing a tree he lost his footing and fell on to a thick branch 5 to 6 metres lower down. The branch penetrated the left side of his chest. He was brought directly to hospital.

Examination.-He was pale, sweating and apprehensive. An irregular laceration $4 \mathrm{~cm}$. long was 


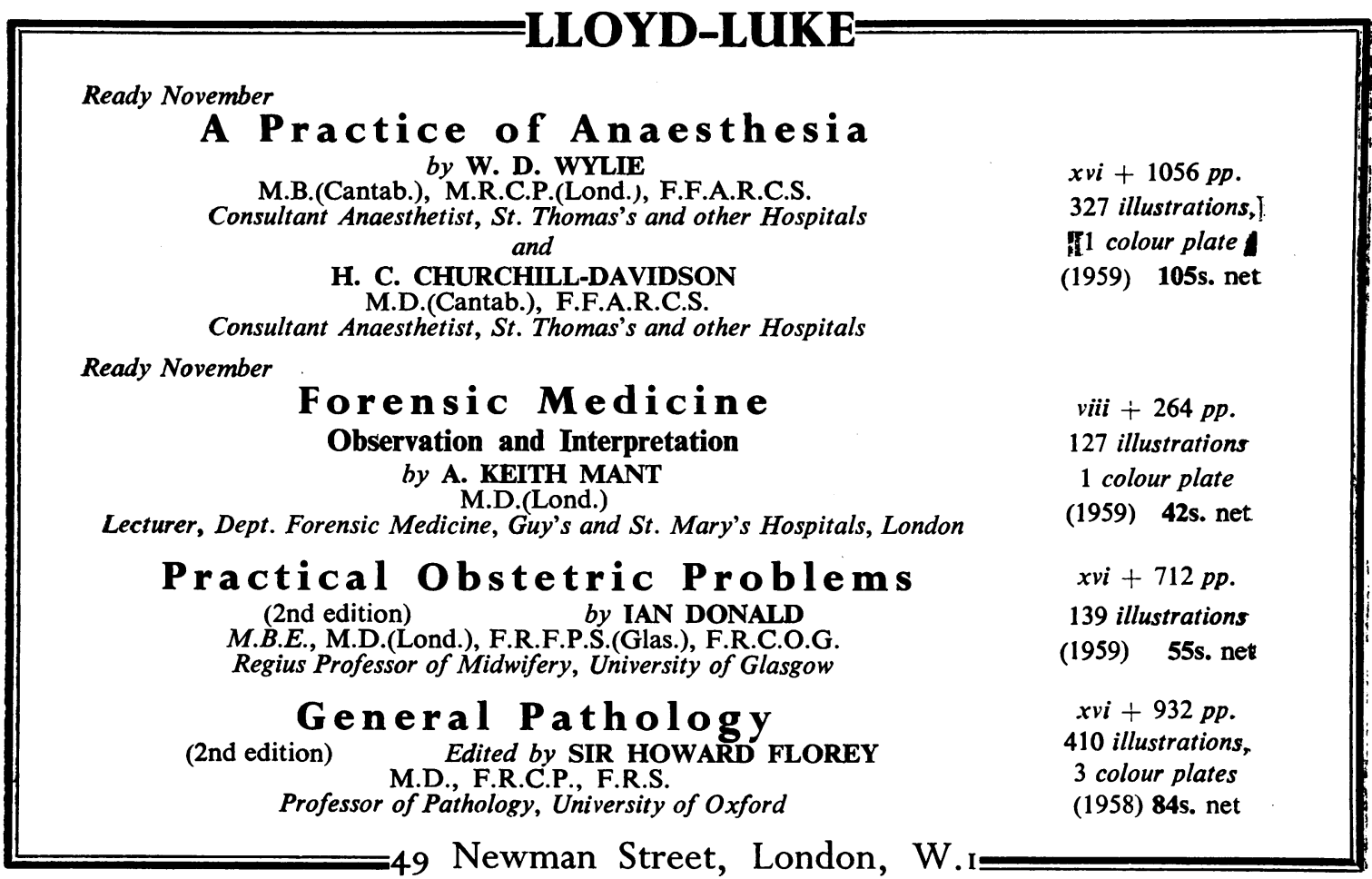

situated over the anterior part of the left 6th and 7 th ribs in the mid-clavicular line. Air was sucking in and out through the wound. A vaseline pack was immediately applied. B.P. was $90 / 60$, pulse a little thready and regular, at the rate of roo/minute. Heart sounds were well heard and a pericardial to and fro murmur was heard at inspiration. Clinical signs of collapse of the left lung were present. Slight tenderness but no guarding was present in the left hypochondrium.

Treatment.-X-ray examination of the chest showed no evidence of rib fracture or intrathoracic foreign body. The lower lobe of the left lung was collapsed and there was a small pneumothorax. After preliminary transfusion of I pint of blood, the patient was taken to the operating theatre. Under general anaesthesia the skin edges of the wound were excised and the left chest opened by extending the wound in the 6th intercostal space. Some blood was present in the pleural cavity. The lingula and the lower portion of the upper lobe of the left lung were bruised but not torn. The left upper part of the pericardium was lacerated for about $3 \mathrm{~cm}$., leaving exposed the left auricle and part of the left atrium, which were bruised and abraded. The torn pericardium had ragged edges, with numer- ous ingrained bits of wood and dirt. The pericardium was freely incised along the left side and the heart examined. No abnormality, except for a little blood in the pericardial sac, was found. The soiled pericardial edges were excised and several loose stitches inserted to approximate the pericardium. The diaphragm was incised. No blood was seen in the peritoneal cavity and the spleen was normal. The diaphragm was closed and then the chest with a temporary intercostal drain.

Progress.-Convalescence was satisfactory except for a left lower lobe pneumonia and a sanguinous pleural effusion which subsided after aspiration and administration of antibiotics. $\mathrm{He}$ was discharged home after three weeks and went back to school a month later, sign- and symptomfree. E.C.G. changes: inverted T waves in leads 3 and A.V.F. became upright three weeks after the operation.

\section{Discussion}

In both cases, realizing that intrathoracic injury had occurred, the wound was extended so as to allow thorough exploration of the left pleural cavity. When it was perceived that the pericardium had been penetrated, the pericardium was widely opened and the heart and great 
vessels inspected. Treatment was instituted according to general surgical principles of toilet and suture.

In Case 2 small pieces of wood and dirt were ingrained into the edges of the pericardial tear, necessitating excision of the affected pericardium. In Case I the left ventricular laceration was clean. It probably involved three-quarters or more of the myocardial wall. A weak scar, with its attendant dangers, was avoided by repair. Cardiac tamponade did not occur, because of minor bleeding and an opening of sufficient size in the pericardium.

The teaching of Hippocrates, Aristotle, and Galen to regard cardiac wounds with a fatalistic mysticism without any hope of salvage was adhered to for many centuries. In spite of animal experiments, observations on human cases (Block, 1882; Senac, 1749) and compilation of $45^{2}$ cases by Fischer (1868), Paget in 1896 stated: 'Surgery of the heart has probably reached the limits set by nature to all surgery; no new method and no new discovery can overcome the natural difficulties that attend a wound of the heart. It is true that " heart suture" has been vaguely proposed as a possible procedure and has been done on animals, but I cannot find that it has ever been attempted in practice.' The same year Cappelen, and a year later Rehn (1897), published their papers on human cardiac suture.

About World War II the high mortality rate of cardiorrhaphy (25-30 per cent.) associated with recovery of selected cases (with or without tamponade) dealt with non-operatively began the era of increased emphasis on the conservative management of penetrating cardiac wounds (Blalock and Ravitch, 1943; Bigger, 1940; Elkin and Campbell, 195I). Many surgeons still adhere to this view, operating only when definite criteria present (I) tamponade unrelieved by pericardiocentesis because of clots, (2) rapid recurrence of tamponade, (3) continuing haemorrhage externally or into the thoracic or abdominal cavity.

Others (Maynard, Cordice and Naclerio, 1952; Naclerio, Maynard and Cordice, I953; Griswold and Drye, 1954) believe that surgical intervention should be immediate, irrespective of the circumstances.

There is little doubt that the two cases reported in this paper were given the best chance by thoracotomy. Maguire and Griswold (1947) had three deaths from 36 cases, Jordan and Wilson (1953) three deaths from 24 cases, and Lyons and Perkins (1957) two deaths from I4 cases.

Most cases of cardiac wounds in civilian practice are admitted to acute general surgical units not used to cardiac surgery, the surgeon also not having any special experience in that field. $\mathrm{He}$ should be able to carry out thoracotomy and in most cases, using elementary surgical principles $\varrho$ of toilet and suture, be able to save more lives than by procrastination. Both of the patients described here were thus treated and both have $\stackrel{.}{\Rightarrow}$ made a full recovery. Even if massive bleeding $\underset{\vec{S}}{\stackrel{\vec{S}}{2}}$ is encountered on opening the pericardium, it is $\overline{0}$ unlikely for the tear to be extensive, because the 흐 patient survived his journey to the theatre. $\frac{\bar{c}}{\sigma}$ Digital pressure and underrunning stitches would $\mathbb{\otimes}$ soon control the bleeding. This applies equally to foreign bodies lodged in the myocardium. Specialized equipment and skill is needed to remove a foreign body from one of the cavities of the heart. Should a general surgeon encounter $\omega^{\omega}$ this at exploration, his prime purpose should be $\overline{8}$ to save life by suturing the perforation and trans- 3 ferring the case to the care of a thoracic surgeon $\omega_{j}$ as soon as possible.

Conservative management includes such measures as intravenous infusions, pericardiocentesis, of prevention of infection and other supportive $A$ treatment, until surgical facilities are available 은 and the need for operation established. There remains, however, uncertainty about the extent $\bigcirc$ of intrathoracic damage, possibility of rapidly $\frac{?}{0}$ progressive tamponade, inability to aspirate a $\underset{\mathbb{D}}{ }$ major proportion of pericardial blood due to clotting, massive secondary haemorrhage, retained of foreign bodies, subsequent sepsis, pericardia effusion, possibly later giving rise to chronie constrictive pericarditis (Ehrenhaft and Taber, 1952), weak myocardial scarring and the potential danger of a blind manoeuvre such as the peri- ֻँ cardial tap, even though the needle acts as a $\varnothing$ praecordial lead of a continuously recording $\overrightarrow{\overrightarrow{0}}$ E.C.G. (Bishop, Estes and McIntosh, 1956). 궁 The conservative medical approach has no place in the treatment of penetrating wounds of the aorta and other great vessels. These may be -0 involved and delay in surgical intervention invites fatal haemorrhage (Harken, 1946; Jahnke and Seeley, 1953).

Fifteen per cent. of 456 cases examined at $\frac{\delta}{3}$ post-mortem by Parmley, Mattingly and Manion

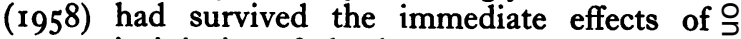
traumatic injuries of the heart or aorta. Death $D$ in most cases was due to a complication amenable to surgical treatment. There is still some truth $N$ in Strieder's (1939) statement: 'Not operating upon a patient with a stab wound of the heart is a very hazardous course to follow.'

\section{Summary}

Two cases of penetrating thoracic wounds involving the heart are described. They were $\stackrel{\mathcal{P}}{+}$ treated by immediate exploration, debridement ${ }^{\circ}$ and suture. Patients with these injuries usually $\frac{\vec{\Phi}}{\Phi}$ 
present in general surgical units. The desirability of prompt exploratory thoracotomy is stressed.

\section{Acknowledgments}

I should like to thank Professor A. M. Boyd and Mr. G. O. Jelly for permission to report these cases and for their helpful advice.

\section{BIBLIOGRAPHY}

BIGGER, G. A. (1940), Med. Ann. Distr. Columbia, 9, 390. BISHOP, L. H., Jr., ESTES, E. H., Jr., and McINTOSH, H. D. (1956), f. Amer. med. Ass., 162, 264.

BLALOCK, A., and RAVITCH, M. M. (1943), Surgery, 14 , 157. BLOCK (1882), 'Verhandlungen der deutschen Gesellschaft für Chirurgie, elften Congress, Berlin,' Part I, p. 108

CAPPELEN, A. (1896), Norsk Mag. Laegevid., 11, 285.

EHRENHAFT, J. L., and TABER, R. E. (1952), f. thorac. Surg., 24, 355 .

ELKIN, D. C., and CAMPBELL, R. E. (1951), Ann. Surg., 133, 623.
FISCHER, G. (1868), Arch. klin. Chir., 9, 571.

GRISWOLD, R. A., and DRYE, J. C. (1954), Ann. Surg., 139, 783.

HARKEN, D. E. (1946), Surg. Gynec. Obstet., 83, 117.

JAHNKE, E. J., Jr., and SEẸLEY, S. F. (1953), Ann. Surg., 138 158.

JORDAN, P., Jr., and WILSON, G. E., Jr. (1953), Surg. Clin. N. Amer., 33, II 5 .

LYONS, C., and PERKINS, R. (1957), American Surgeon, 23, 6, 507.

MAGUIRE, C. H., and GRISWOLD, R. A. (1947), Amer. F. Surg., 74, 721.

MAYNARD, A. DE L., CORDICE, J. W. V., Jr., and NACLERIO, E. A. (1952), Surg. Gynec. Obstet., 94, 605 .

NACLERIO, E. A., MAYNARD, A. DE L., and CORDICE J. W. V., Jr. (1953), Y. thorac. Surg., 25, 448.

PAGET, S. (r896), 'The Surgery of the Chest,' London, p. 121.

PARMLEY, L. F., MATTINGLY, T. W., and MANION, W. C. (1958), Circulation, 17, 5, 953.

REHN, L. (1897), Arch. klin. Chir., 55, 315.

SENAC, J. B. (1749), 'Traite de la structure de coeur, de son action et de ses maladies,' Paris, 2, 366

STRIEDER, J. W. (1939), f. thorac. Surg., 8, 576.

\section{HOW TO GET THERE}

An Address Book for the Medical profession, showing how to reach the various Colleges, Societies, Institutes and Hospitals in or near London

New (Fourth) Edition: 1954

Price 2s. 6d. (3s. Od., post free)

Published by the

\section{FELLOWSHIP OF POSTGRADUATE MEDICINE}

60 Portland Place, London, W.I

Bibliography continued from page 545-F. G. Smiddy, F.R.C.S.

\section{BIBLIOGRAPHY}

CHAMBERS, R., and ZWEIFACH, B. W. (1947), Amer. F. Physiol. I50, 239.

COOPER, Sir A. (1838), 'A Dictionary or Surgery,' 7th edition, London, Longman.

FARR, R. S., CLARK, S. L., and PROFFITT, J. E., Research Report, Naval Res. Inst., U.S.A., Project N.M. 00708 I, $12,02$.

FINE, J., FRANK, H. A., SCHWEINBURG, F. B., JACOB, S. W., and GORDON, T. (1952), Ann. N.Y. Acad. Sci., 55,429 .

FINE, J. (1958), Brit. F. Anaesth., 30, 455

FRANK, H. A., SELIGMAN, A. M., and FINE, J. (1946), f. clin. Invest., 25, 22.

FRANK, E., FINE, J., and PILLEMER, L. (1955), Proc. Soc. exp. Biol. (N.Y.), 89, 223.

FRANK, N. A., JACOB, S. W., FREIDMAN, E. E., RUTENBURG, S. H., and FINE, J. (1952), Amer. F. Physiol., 168, 150.

GREEN, S., MAZUR, A., and SHORR, E. (1956), f. biol. Chem., 220, 237.

JACOB, S. W., WEIZEL, H., GORDON, E., KORMAN, H., SCHWEINBURG, F. B., FRANK, H., and FINE, J. (I954), Amer. F. Physiol., 179, 523.

LANDY, M. J., and SHEAR, M. J. (1957), f. exp. Med., 106, 77. LeDRAN, H. F. (1943), A treatise, or 'Reflections Drawn from Practice on Gunshot Wounds '(translated), London, Clarke.
RAVIN, H. A., RUTENBURG, S. H., and FINE, J. (1958), Proc. Soc. exp. Biol. (N.Y.), 97, 436 .

RUTENBURG, S. H., and FINE, J. (1956), Ibid., 93, 484.

SCHWEINBURG, F. B., FRANK, H. A., and FINE, J. (1954), Amer. F. Physiol., 179, 532.

SCHWEINBURG, F. B., and FINE, J. (1955) Proc. Soc. exp. Biol. (N.Y.), 88, 589 .

SCHWEINBURG, F. B., SHAPIRO, P. B., FRANK, E. D., and FINE, J. (1958), Ibid., 95, 646 .

SHORR, E., ZWEIFACH, B. W., and FURCHGOTT, R. F. (1948), Ann. N.Y. Acad. Sci., 49, 571.

SHORR. E., ZWEIFACH, B. W., FURCHGOTT, R. F., and BAEZ, S. (195I), Circulation, 3, 42.

SMIDDY, F. G., and FINE, J. (1957), Proc. Soc. exp. Biol. (N.Y.), 96, 558 .

WEIL, M. H., MCCLEAN, L. D., VISCHER, M. B., and SPINK, W. W. (I956), Ұ. clin. Invest., 35, I 191 .

ZWEIFACH, B. W., LEE, R. E., HYMAN, C., and CHAMBERS, R. (1944), Ann. Surg., 120, 232.

ZWEIFACH, B. W., and THOMAS, L. (1957), f. exp. Med. 106, 385 .

ZWEIFACH, B. W., GORDON, H. A., WAGNER, M., and REYNIERS, J. A. (1958), Ibid., 107, 437.

ZWEIFACH, B. W., BENACERRAF B., and THOMAS, L. (1958), Ibid., ro6, 403 . 